\title{
Rice Transplanting Machine
}

\author{
Pankaj kumar singh ${ }^{*}$, Harischand srivastav ${ }^{*}$, Abhikekh kumar bind ${ }^{*}$, \\ Chandan kumar, Mr. Rohit Jain ${ }^{* *}$ \\ *Bachelor of Technology, \\ *** Assistant Professor \\ Mechanical Engineering Department, United College of Engineering and Management, Allahabad, India
}

\begin{abstract}
Manual method of seed planting, results in low seed placement, spacing efficiencies and serious back ache for the farmer which limits the size of field that can be planted. The cost price of imported planters has gone beyond the purchasing power of most of our farmers. Peasant farmers can do much to increase food production especially grains, if drudgery can be reduced or totally removed from their planting operations. To achieve the best performance from a seed planter, the above limits are to be optimized by proper design and selection of the components required on the machine to suit the needs of crops. Need of rice trans-planter machine is growing nowadays because it unique features seeding in well sequence and in well manner. Seeding by rice trans-planter saves too much efforts of human being. Class of people who uses this kind of machines is farmers and they are having poor economic background. This paper provides guidelines for developments in rice Trans-planters used in India. Rice planting is very old method from many years ago \& having long history since many years \& their methods of rice planting are changed in this decade. Use of rice Trans planter machines is new trend but current machines having high cost of purchase. So the main focus of this project is to minimize the cost of that machine.

Keywords: Rice planter, cost minimization, design \&development.
\end{abstract}

\section{INTRODUCTION}

Rice being the important food crop covers about one fourth of the total cropped area and cater food to half of the Indian population. In India, average rice production per hectare is 2.2 tonne.

[1]. Climatic condition such as temperature and humidity plays a vital role in rice production. Rice production mainly involves the following three steps: (i) Pre-Planting (ii) Postproduction (iii) Growth. North Eastern India is considered to be potential region for rice production. North Eastern India covers 7.8 percent of the total area of rice cultivated in India and in terms of rice production, accounts to only 5.9 percent of the total national rice production.

[2]. However, this region is lagging in terms of rice production because of labour intensive work. Rice cultivation mainly depends on the following factor (i) age of the variety (ii) availability of moisture (iii) climatic conditions (iv) Availability of inputs and labour. Among these reasons, availability of inputs and labour play a huge role on deciding the method of production of rice. Several attempts has been made to mechanize paddy transplanting operation by introducing various transplanters and research is under progress to reduce the cost of production with less fatigue. Local transplanting requires frequent bending down and straighten up for transplanting process where as mechanical transplanter requires energy for pulling the transplanter in puddled field. Due to the high price of an automated paddy transplanter, it becomes impossible for a small scale farmer to buy a non-subsidized automated paddy transplanter. An attempt has been made to fabricate a manual operated paddy transplanter which is effective as well as cheap.

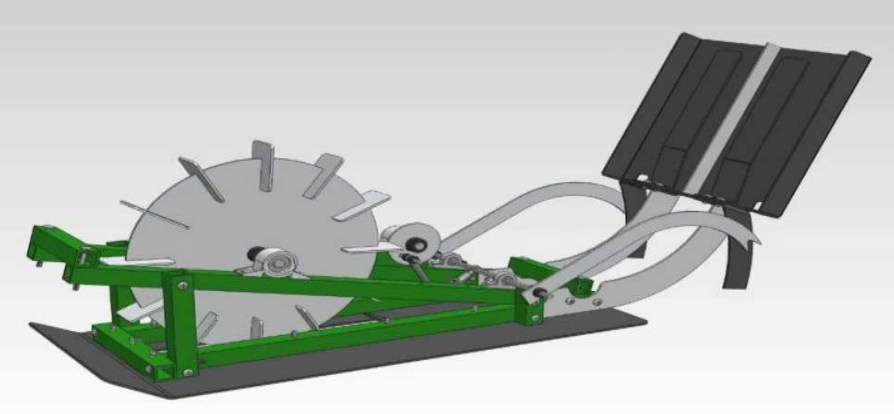

Fig.1 Basic Fig. of rice transtlanter 


\section{RESEARCH METHODOLOGY Selection of Area of research}

Farmers are not aware of the advantages associated with transplanting of paddy over the broadcasting. But they are unable to practice it for high scarcity of labor. Still the transplanting machines available for the country are imported. Engine driven transplanters are high in cost and the inter-raw, intra-raw spacing are fixed which are not suitable for the Indian condition. Existing manually operated transplanters are inefficient. The main reason for the poor acceptance was the law capacity of the machine. A simple engine operated transplanter or manually operated transplanter having an average capacity of one hectare per day would be a better solution.

\section{Method of establishments}

Here are two methods practices in establishment of paddy in India. Those are direct sowing / seeding and Transplanting. 1 Direct sowing / seeding there are two types- Wet seeding \& dry seeding. Wet seeding Pre germinated seeds are used to broad-casted into puddled as well as leveled fields which are free from standing water. At same time of puddling basal fertilizer must be added in it. Spraying should be done when seedlings will come up to 10 inches long. The stand establishment by this method varies with the quality of land preparation, weed competition, water management \& rain water during the first period after sowing. Dry seeding unterminated dry seeds are sown into dry mud in orientation as per requirement. Rate of seed varies with the conditions \& the type of physical damages \& impurities of the seeds. Rate of seed varies from $145 \mathrm{Kg} / \mathrm{ha}$ to $290 \mathrm{Kg} / \mathrm{ha}$ depending on the level of weed infestation in dry seeded rice. Well development of plant, No transplanting shock to the plant, Suitable method for short duration varieties.

\section{LITERATURE REVIEW}

A ricetransplanter is a specialized machine used to transplant rice seedlings in the field. A common rice transplanter comprises:

- A seedling tray like a shed roof on which mat type rice nursery is set.

- A seedling tray shifter that shifts the seedling tray like the carriage of typewriters.

- $\quad$ Plural pickup forks that pick seedlings up from mat type nursery on the seedling tray and put the seedlings into the earth, as if the seedling were taken between human fingers.

Machine transplanting using rice transplanters requires considerably less time and labor than manual transplanting. It increases the approximate area that a person can plant from 700 to
$10,000 \mathrm{~m}^{2} /$ day .Transplanting of paddy seedlings can be categorized into three groups as follows:

1. By band (manual)

2. Manually operated machines (work by man power)

3. Mechanically operated machines (work by engine power)

\section{DESIGN OF SYSTEM}

For frame design as shown in the figure 6, let us assume that Mass of rice plants is $5 \mathrm{~kg} \&$ Mass of frame and accessories is $20 \mathrm{~kg}$.

Total Mass $(\mathrm{M})=25 \mathrm{~kg}$ (Assuming)

Total Force $(\mathrm{F})=\mathrm{M} \times \mathrm{g}$-----(1A)

Where $(\mathrm{g})$ is acceleration due to gravity

$\mathrm{F}=25 \times 9.81 \mathrm{~N}$

$\mathrm{F}=981 \mathrm{~N}$

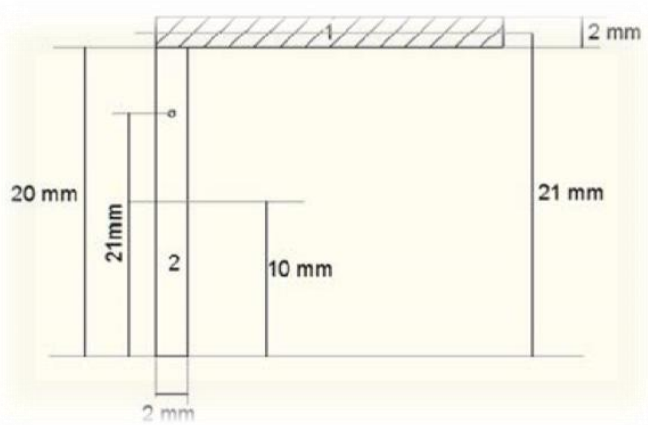

Fig 4: Layout view of frame

There are four key points where total weight acts on links, so considering load is distributed equally at each point i.e. each link. Force acting on each link is given by

$\mathrm{F} 1=\mathrm{F} / 4$

$\mathrm{F} 1=981 / 4=245.2 \mathrm{~N}$

Length of link 1 is $910 \mathrm{~mm}$ so bending moment (M) for link 1 is given by $\mathrm{M}=\mathrm{F} 1 \times \mathrm{L} 1$------- $(3 \mathrm{~A})$

$\mathrm{M}=245.25 \times(910 / 1000)$

$\mathrm{M}=223.17 \mathrm{~N}-\mathrm{m}$

We are using MS angle over MS flat because MS angle has comparatively high strength in twisting \& bending than MS flat. So selecting MS angle of $(22 \times$ $22 \times 2)$ mm dimensions.

Calculating Moment of Inertia for MS angle $(\mathrm{Ig}) \mathrm{Ig}=\left(\mathrm{b} \times \mathrm{d}^{3} / 12\right)$ permissible $=$ Sut $/ \mathrm{Nf}$

$\sigma$ permissible $=650 / 2=325 \mathrm{~N} / \mathrm{mm}^{2}$

$\mathrm{I}_{\mathrm{G} 1}=\left(22 \times 2^{3}\right) / 12=14.666 \mathrm{~mm}^{4} \mathrm{I}_{\mathrm{G} 2}=\left(20^{3} \times 2\right) / 12=$ $1333.33 \mathrm{~mm}^{4} \mathrm{y}=$ C.G. of the system $=\left(\mathrm{A}_{1} \mathrm{y}_{1}+\right.$ $\left.\mathrm{A}_{2} \mathrm{y}_{2}\right) /\left(\mathrm{A}_{1}+\mathrm{A}_{2}\right)$

(5A)

$y=[\{(22 \times 2) \times 2\}+\{(20 \times 2) \times 10\}] /\{(20 \times 2)+$

$(22 \times 2)\} \mathrm{y}=$

$15.76 \mathrm{~mm}$

Now, $\mathrm{I}_{\mathrm{P}}=$ Moment of Inertia about parallel axis. $\mathrm{Ip}=\left(\mathrm{I}_{\mathrm{G}}+\mathrm{Ah}^{2}\right)$ 
So, IP1 = (IG1+A1 h12)

$\mathrm{I}_{\mathrm{P} 1}=14.666+\left\{44 \times(21-15.76)^{2}\right\}$

$\mathrm{I}_{\mathrm{P} 2}=1222.80 \mathrm{~mm}^{4}$

$\mathrm{IP} 2=(\mathrm{IG} 2+\mathrm{A} 2 \mathrm{~h} 22)$

$\mathrm{I}_{\mathrm{P} 2}=1333.33+\left\{40 \times(15.76-10)^{2}\right\}$

$\mathrm{I}_{\mathrm{P} 2}=2660.434 \mathrm{~mm}^{4}$

So, Moment of inertia

$\mathrm{I}=\mathrm{I}_{\mathrm{P} 1}+\mathrm{I}_{\mathrm{P} 2} \mathrm{I}=$

$1222.80+2660.434$

$\mathrm{I}=3883.234 \mathrm{~mm}^{4}$

We know that,

$$
\begin{aligned}
& (\mathrm{M} / \mathrm{I})=(\sigma / \mathrm{y}) \\
& \sigma_{\text {actual }}=(\mathrm{Mxy}) / \mathrm{I} \\
& \sigma_{\text {actual }}=\left(223.17 \times 10^{3} \times 15.76\right) / \\
& 3883.234 \sigma_{\text {actual }}=90.572 \mathrm{~N} / \mathrm{mm}_{2}
\end{aligned}
$$

As, $\sigma_{\text {actual }}<\sigma_{\text {permissible }}$ So, Design is safe

\section{CONSTRUCTION AND WORKING}

1 Ground Wheel: - It is wheel which is contact on ground. It mounted on driver shaft. Its motion gives to the quick return mechanism through the chain drive. On the periphery of this wheel, blade is mounted to achieve proper grip in mud.

2 Sprockets: - The main function of sprockets is to transmit torque through chain. There are two sprocket-one drivers and other driven mounted on respective shafts

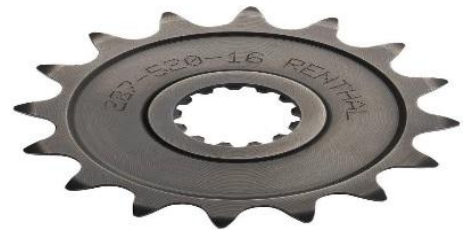

3 Chain: - The function of chain is to transmit torque from driver to driven sprockets. The chain is simplex type

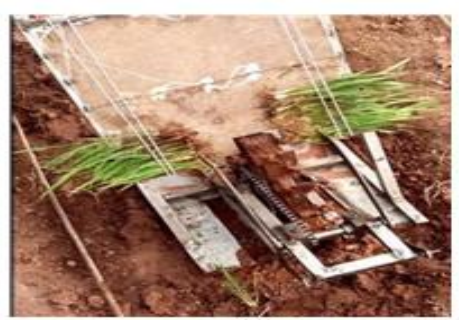

(a)

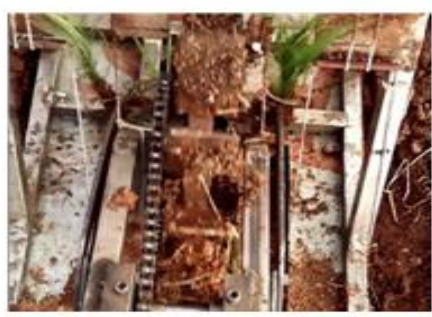

(d)

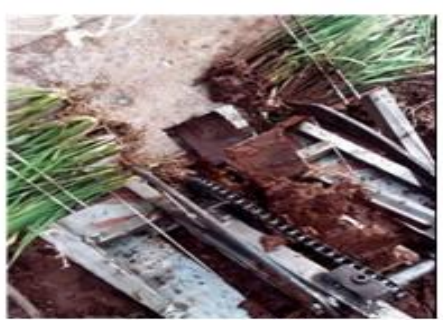

(b)

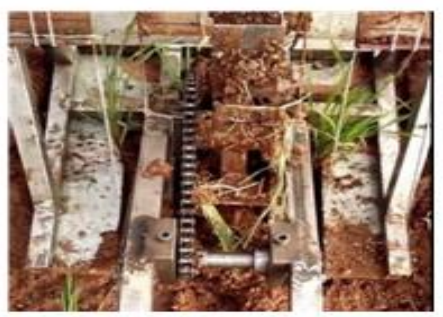

(e)

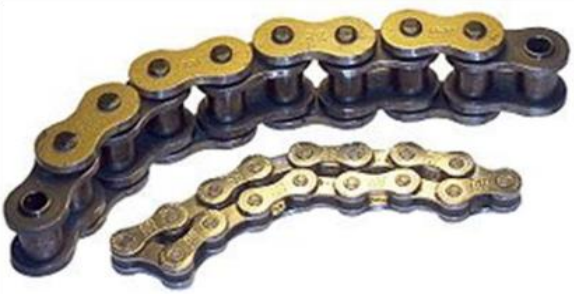

4 Tray: - This is used to store the rice plant from where the planting finger pick the plant and saw in the ground. This tray has two vertical guide slots.

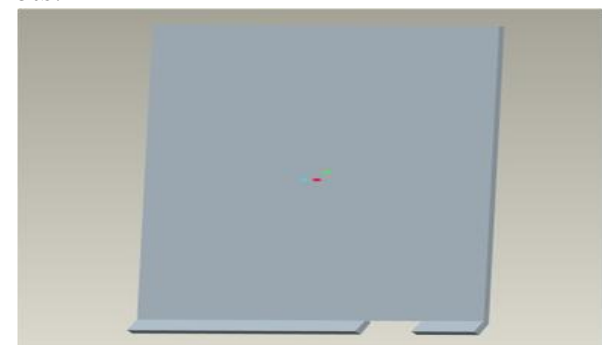

5 Planting Finger: - The planting finger is the main element which is responsible for the plantation of the nursery seed. It has the specific shape which picks the nursery seed and plant in mud. It oscillates at certain angle and it is called as fixed fork mechanism.

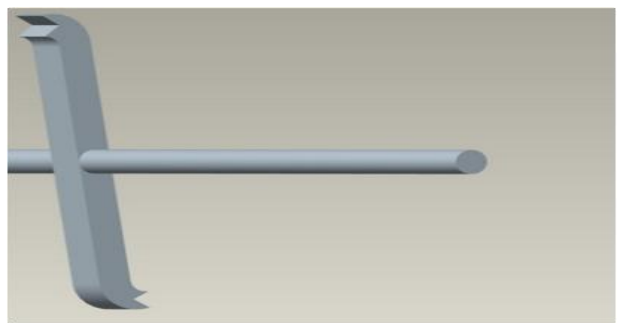


Fig (a) initial position, fig (b) picking the plant, fig (c) start to lower down, fig (d) process of lower down, fig (e) start to digging plant, fig (f) finishing of digging of plant.

\section{Working}

As the process is manual the worker has to provide the initial motion. When the rice transplanter will move forward the ground wheels will get rotate. The wheels are provided with the fins so that they can travel easily in the mud. The ground wheels are used to maintain constant distance between the two successive plants. Then we have larger sprocket is provided on the same shaft with the ground wheels and hence at the same time sprocket will also rotate. Sprocket is in engagement with the smaller sprocket by using the chain drive. As the power will get transmitted to the smaller sprocket, it will rotate. The speed is increased from driver to driven shaft as we used 3:1 bar linkage so that it will oscillate for certain angle. As the drive is provided by the worker it will not have high speed and hence through this sprocket arrangement we have increase the planting finger speed. As the planting speed ratio. On the same shaft planting finger will be fixed through the four finger will oscillate, it will pick the rice plant from the tray and plant in mud. The planting finger is designed in such a way that rice plant should be easy to pick during the motion and also it should pick duringthe downward motion only.

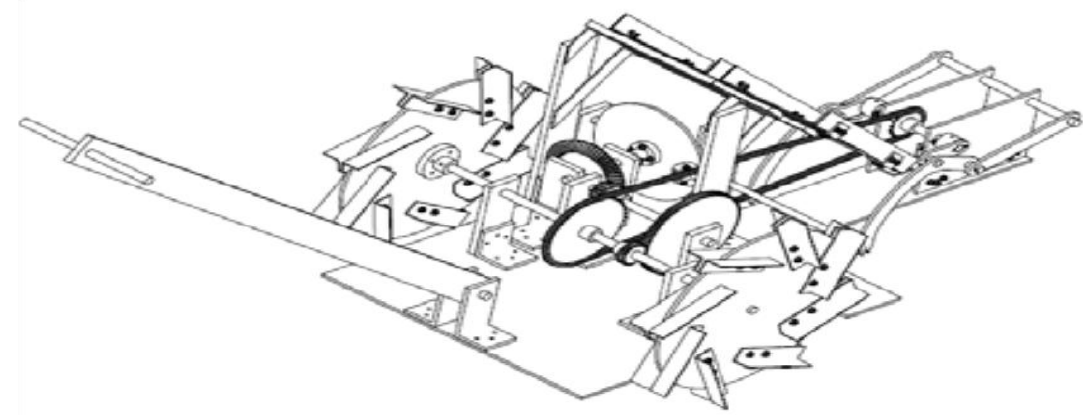

Fig 14: Market Available Planter Machine

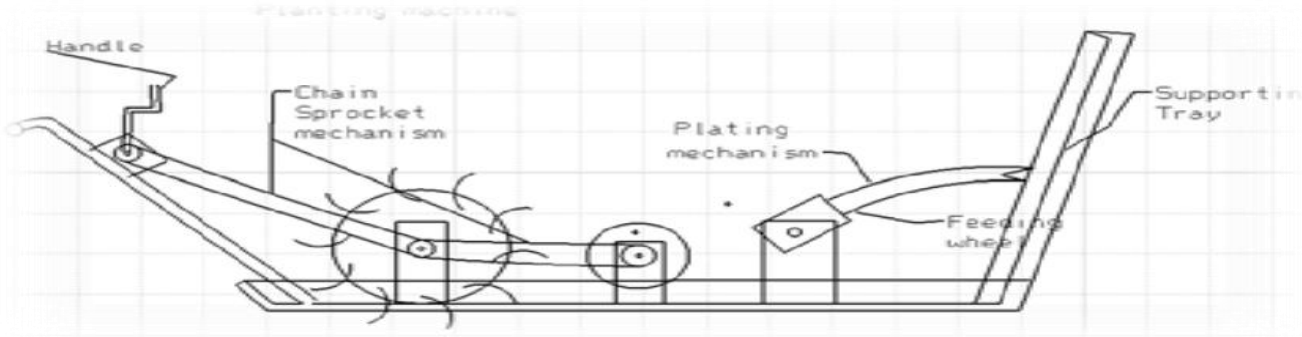

Fig. 15: Proposed system for Planter Machine

Rice planter are available in wide range and verity of several things in the agriculture market. But all this planter machines having complex mechanism and large number of parts which leads to increase in cost.

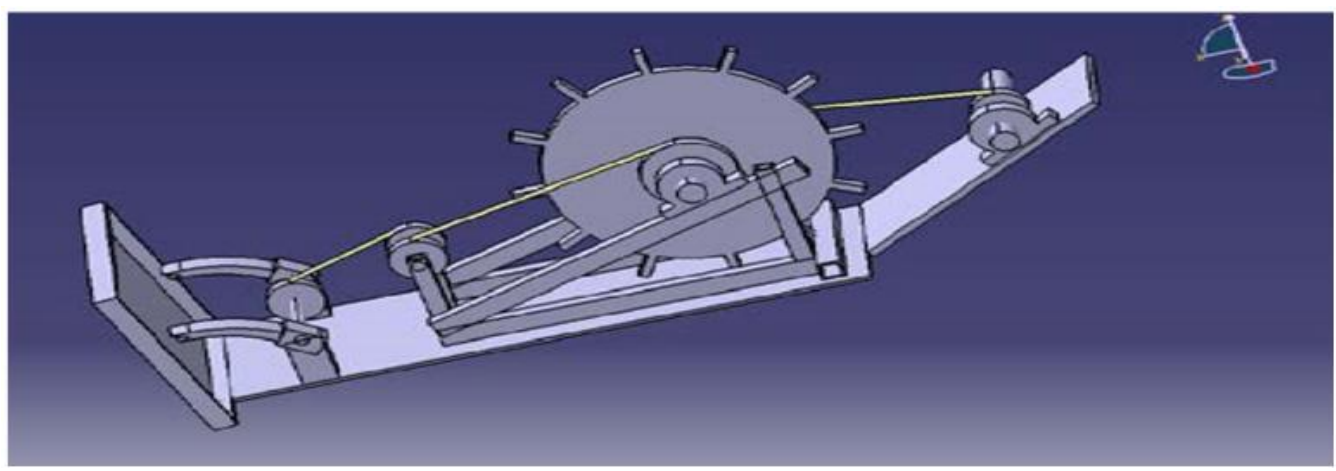

Fig 16: CATIA Model of Rice Transplanter 
Additional parameters also provided which regular planter machines don't have in certain range of cost. This parameters contains height adjuster of

\section{RESULTS AND DISCUSSION}

Prototype mechanism was evaluated in the field, and it worked. There were some points to be redesigned. Tray mechanism worked but the design should be altered or improved. The tray move to both left and right directions while the tray on a grove. That resulted high friction. Therefore it is better to have nylon bushes and iron or aluminum rods to reduce the friction. Tray moving mechanism made using nylon sprocket wheel. As the tension is high in that chain the nylon sprocket get damaged easily. It's better to use iron sprocket with same diameter and number of teeth to reduce the damage when tension is high. The sprocket and chain used for the machine was foot cycle chains and sprockets. When machine is operated the sprockets get damaged by bending the teeth. So it is better to have motorcycle chains and sprockets to power transmission. But that will result an increase in weight. Therefore, instead of chain and sprocket speed reducing mechanism, a gear system should be used.

\section{CONCLUSIONS AND RECOMMENDATIONS}

The paddy seedling transplanting machine worked satisfactorily. But, there were some improvements to be done before introducing to the farmers. The machine is driven by man power but engine can be coupled to enhance the performances. Machine can be developed to transplant several rows simultaneously. Weight of the machine should be reduced by removing sprocket, chains and adding small gears. The dapog must have thin mud layer for easy removal of seedlings.

\section{REFERENCES}

[1] Singh G, Sharma T R. and Bockhop C W. 1985. Field performance evaluation of a manual rice transplanter. Journal of Agril. Engg. Research. Vol. 32, Issue 3, pp. 259268.

[2] Goel A C. and Verma K S. 2000. Comparative study of directly seeding and transplanted rice. Indian J. Agril. Research, 34(3): 194-196.

[3] Patra A K. and Nayak B C. 2001. Grain yield of rice under different spacings. Indian Jr. of Agronomy, 46(3): 449-452.

[4] Obulamma U and Reddy R. 2002. Effect of spacing and seedling number on growth and yield of hybrid rice. Journal of Research, ANGRAU, 30(1): 76-78.

[5] Khan A S. and Gunkel, W W. 1988. Design and development of a 6-row Korean main wheel, depth adjuster of picking arm, additional power source to drive the wheel etc.

transplanter, Agril. Mechanization in Asia, Africa and Latin America (AMA), 19(1): 27-34. 